Глава 6. Физиология и биохимия растений

16. Шаззо Р.И., Касьянов Г.И. Функциональные продукты питания - М.: Колос, 2004. -247 c. - ISBN 5-10-003709-1.

17. Яицкая Н.А., Шевердяев И.В., Магаева А.А., Бригида В.С. Реконструкция опасных нагонов в северном Каспии на основе цифровых моделей рельефа дна и гидрологического моделирования // Наука Юга России. - 2021. - Т. 17. - № 3. - С. 18-29. - https://doi.org/10.7868/S25000640210303.

18. Brigida V.S., Mishulina S.I., Stas G.V. Perspective directions of "ecologisation" of structural elements of a tourist product of Krasnodar region (case study of transportation component) // Sustainable Development of Mountain Territories. - 2020. - T. 12. - № 1(43). - C. 18-25. - https:// doi.org/10.21177/1998-4502-2020-12-1-18-25.

\title{
FUNCTIONAL CANNED GOODS BASED ON SUBTROPICAL FRUITS
}

\author{
Akaba A.N. \\ Federal State Budgetary Educational Institution \\ of Higher Education "I.T. Trubilin Kuban State Agrarian University", \\ Krasnodar,Russia,e-mail: aminaakaba96@mail.ru
}

The creation of functional food products is one of the most important problems in the modern development of food industry. The paper provides a comprehensive analysis of literary sources and an experimental study of the chemical composition of subtropical raw materials - feijoa and kiwi fruits. As a result, the paper established a polynomial dependence of the attractiveness score, as well as a linear dependence of the compliance factor on the parameters of the production recipe of feijoa and kiwi fruit jam. Based on the conducted research, the most rational parameters of the jam recipe were determined according to four tasting parameters.

Key words: feijoa, kiwi, nutrients, pectin, recipes, jam, subtropical fruits.

doi: $10.31360 / 2225-3068-2021-79-99-107$

\section{АНАЛИЗ МНОГОЛЕТНЕЙ ДИНАМИКИ СОДЕРЖАНИЯ ХИМИЧЕСКИХ КОМПОНЕНТОВ пЛОДОВ СЛИвЫ}

\author{
Дубровская О.Ю., Жбанова Е.В., Богданов Р.Е. \\ Федеральное государственное бюджетное научное учреждение \\ "Федеральный научный иентр им. И.В. Мичурина», \\ 2. Мичуринск, Россия, e-mail: popova_olya8888@mail.ru
}

Изучена динамика содержания компонентов химического состава плодов сливы за вегетационные сезоны 2018-2021 гг., существенно отличающиеся по значениям среднемесячных температур и суммы осадков. В среднем за период исследования растворимых сухих веществ в плодах накапливалось $10,8-16,2 \%$, сахаров - 8,1-9,2 \%, титруемых кислот $-1,5-3,4 \%$, витамина C - 4,3-10,5 мг/100 г. Сахарокислотный индекс изменялся в пределах от 4,1 
до 4,4. У изучаемых сортов сливы за период проведения исследований положительные корреляции высокого уровня отмечены между содержанием растворимых сухих веществ и суммы сахаров в плодах (на уровне 0,99 ), а также между содержанием витамина С и титруемой кислотностью $(0,88)$. Также отмечено положительное влияние достаточного увлажнения на уровень накопления сахаров, растворимых сухих веществ и витамина $\mathrm{C}$ в плодах. Между значениями среднемесячных температур летнего периода и содержанием витамина С наблюдалась отрицательная корреляция.

Ключевые слова: слива, химический состав плодов, растворимые сухие вещества, сумма сахаров, содержание витамина С, титруемая кислотность, климатические условия.

Плоды являются важным компонентом сбалансированного питания человека, так как содержат комплекс ценных химических соединений витаминов, органических кислот, углеводов, антиоксидантов, клетчатки и др., необходимых для нормального протекания основных физиологических процессов в организме.

Слива является одной из важнейших косточковых культур, выращиваемых в мире. Её сорта в целом характеризуются широкой экологической пластичностью, пригодностью для механизированных технологий возделывания и возможностью использования плодов как в свежем виде, так и для хранения или различных направлений переработки с созданием соответствующих консервированных продуктов питания.

Сортовые особенности, условия выращивания и погода влияют на химический состав плодов [1, 2]. В условиях Краснодарского края отмечено, что в засушливые годы у сливы домашней возрастало содержание сахаров и антоцианов. Наибольшее содержание растворимых сухих веществ (РСВ) выявлено в плодах сливы сорта 'Красотка' (21,8 \%), 'Милена' (20,8 \%), 'Чачакская улучшенная' $(18,4$ \%) и 'Стенлей' $(18,2 \%)$. Содержание сахаров в изученной группе сортов в среднем составило 11,7 \%. Увеличению кислотности плодов способствовали обильные осадки, в эти же годы отмечено повышенное содержание аскорбиновой кислоты. Сорта 'Краснодарская', 'Герцог' и 'Чародейка' отличались повышенным накоплением титруемых кислот на уровне 1,8 \%, 1,3\% и 1,2\%, соответственно [9].

Многолетние исследования химического состава плодов различных сортов сливы, произрастающих в условиях предгорной зоны Кабардино-Балкарской республики показали, что при пониженной сумме активных температур и повышенной влажности воздуха в них накапливалось наибольшее количество аскорбиновой кислоты, но при этом снижался уровень содержания сухих веществ (РСВ), сахаров и кислот. Более высоким содержанием РСВ отличались сорта 'Кабардинская 
Глава 6. Физиология и биохимия растений

плотная’ (20,8 \%), ‘Чернослив’ (20,6 \%), ‘Аскер’ (18,5 \%). Содержание общего сахара в среднем по сортам составило 10,8 \%, при максимальных значениях 12,8 \% и 12,4 \% - у сортов 'Калифорнийская' и 'Кабардинская плотная', соответственно. Витамина С в плодах накапливалось в пределах от 3,9 до 7,0 мг/100 г, титруемых кислот - 0,46-1,12 \% [12].

В результате изучения плодов сортов и гибридов сливы селекции Татарского НИИСХ выявлено, что содержание сахаров находилось в пределах от 7,1 до 9,5 \%. Также отмечено очень высокое накопление кислот (1,4 до 2,3 \%) и, как следствие, низкие значения сахарокислотного индекса $(3,6-5,5)$. Изменчивость данных признаков в большей степени определялась климатическими условиями года, чем генотипом. Вариабельность количества сухих веществ в плодах между сортами больше зависела от их генотипа. Авторами проведено сравнение местных сортов и гибридов с сортами, произрастающими в условия южных регионов России [10]. Новые отборные формы сливы селекции Татарского НИИСХ по уровню накопления растворимых сухих веществ лишь немного уступали южным сортам, а по содержанию витамина С (10,5-13,3 м/100 г) превосходили их. Содержание титруемых кислот в плодах местных форм было значительно выше, чем у южных сортов, а сахарокислотный индекс - ниже.

На примере сортов сливы 'Toptaste', 'Jojo', 'Haganta', 'Tophit', и 'Тор 2000', выращиваемых в Хорватии, изучена зависимость накопления общего сахара, а также глюкозы, фруктозы, сахарозы и сорбита от температуры и количества осадков. Выявлено, что глюкоза и сахароза накапливаются в плодах в большем количестве, чем фруктоза и сорбит. У сортов 'Јојо' и 'Тор 2000' фруктоза является основным сахаром. Содержание сахарозы за период исследования было высоким и характеризовалось значительной положительной корреляцией с количеством осадков. Накопление сорбитола и сухого вещества отрицательно коррелировало с уровнем осадков. Значимая положительная корреляция отмечена между значением температуры и содержанием сорбитола в плодах, а также между уровнями накопления суммы сахаров и РСВ [13].

Целью нашего исследования являлась оценка изменчивости содержания основных компонентов химического состава плодов сливы в зависимости от температуры воздуха и количества осадков в районе возделывания.

Объекты и методы исследований. Объектом исследования служили свежие плоды сливы сортов 'Евразия 21', 'Светлячок', 'Этюд' из генетической коллекции Федерального научного центра им. И.В. Мичурина, расположенного в г. Мичуринске Тамбовской области. Регион произрастания изучаемых растений характеризуется относительно 
благоприятным комплексом природно-климатических факторов: климат - умеренно континентальный, с выраженной сменой времен года и температурным режимом, пригодным для выращивания многолетних насаждений основных плодовых культур, в том числе и сливы. Сад расположен в средней части восточного склона. Тип почвы - серая лесная. Механический состав неоднороден. Верхняя часть склона представлена лёгким суглинком. По мере понижения рельефа доля крупных (более 0,01 мм) почвенных частиц понижается. Почва также характеризуется бесструктурным составом.

Исследование химического состава плодов проводили в 2018-2021 гг. в период их потребительской зрелости [11]. Содержание растворимых сухих веществ определяли рефрактометрическим методом с помощью рефрактометра ATAGO RX-500 (ГОСТ 28562-90) [5]. Исследование содержания суммы сахаров проводили по методу Бертрана (ГОСТ 8756.1387) [6]. Титруемую кислотность устанавливали титрованием вытяжек 0,1 н раствором $\mathrm{NaOH}$ с помощью титратора METTLER TOLEDO G20S с последующим пересчётом на яблочную кислоту (ГОСТ 25555.0-82) [4, $7,8]$. Экспериментальные данные статистически обрабатывали с использованием пакета прикладных программ Microsoft Office Excel.

Результаты и их обсуждение. Период проведения исследований (2018-2021 гг.) характеризовался существенным различием климатических параметров вегетационных сезонов. Наибольшая вариабельность в указанные годы отмечена по значениям среднемесячных температур и особенно - суммы осадков (рис. 1).
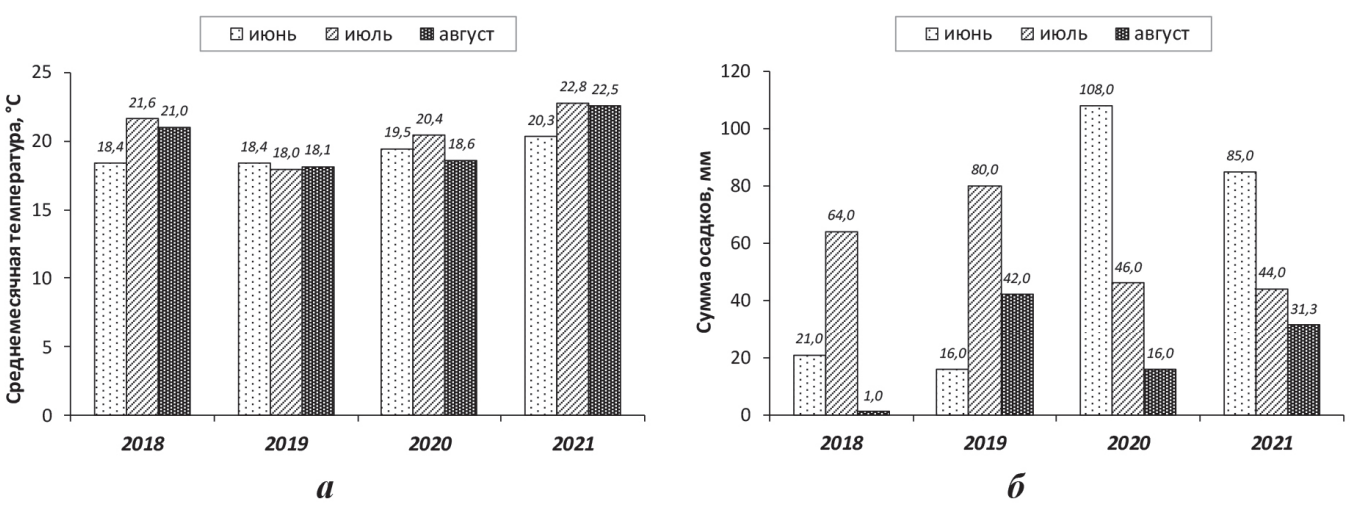

Рис. 1. Динамика изменения среднемесячной температуры $(\boldsymbol{a})$ и суммы осадков (б) в летний период за годы исследований 
Глава 6. Физиология и биохимия растений

Наименьшие среднемесячные температуры летнего периода установлены в 2019 г., а наибольшие - в 2021 г. При этом по температурному режиму летнего периода были сходными показатели 2018 и 2021 гг., характеризующиеся более прохладным июнем и несколько увеличенными, почти одинаковыми температурами июля и августа. Летом 2019 и 2020 гг. температуры по трём месяцам были более выровненными. Наиболее засушливый летний период отмечен в 2018 г., когда за три месяца выпало всего 86 мм осадков, а их максимальное количество на уровне 170 мм зафиксировано летом 2020 г. Летние периоды 2019 и 2021 гг. характеризовались промежуточными значениями суммы осадков -138 и 160,3 мм, соответственно.

За период исследования наблюдались различия химического состава плодов сливы по сортам. Количество растворимых сухих веществ в плодах за годы исследований колебалось от 10,8 \% у сорта 'Светлячок' до 16,2 \% у сорта 'Этюд’. В среднем за время исследования наиболее высокими показателями по данному признаку отличались плоды сорта ‘Этюд’ (15,4 $\pm 0,34$ \%) (рис. 2a).

Уровень накопления сахаров является важным показателем качества плодов и имеет высокую зависимость от погодных условий. В среднем по сортам наиболее высокое содержание сахаров отмечено в 2019 г. (рис. 2б). Среднее содержание суммы сахаров за изученный период составило у сорта 'Этюд’ 9,2 $\pm 0,49$ \%, 'Евразия 21' - 8,8 $\pm 0,17$ \%, 'Светлячок' - 8,1 $\pm 0,69 \%$. Существенные различия уровня накопления сахаров в зависимости от условий года выявлены у сортов 'Светлячок' и 'Этюд’: коэффициент вариации данного показателя по годам составил $17,2 \%$ и $10,6 \%$, соответственно.
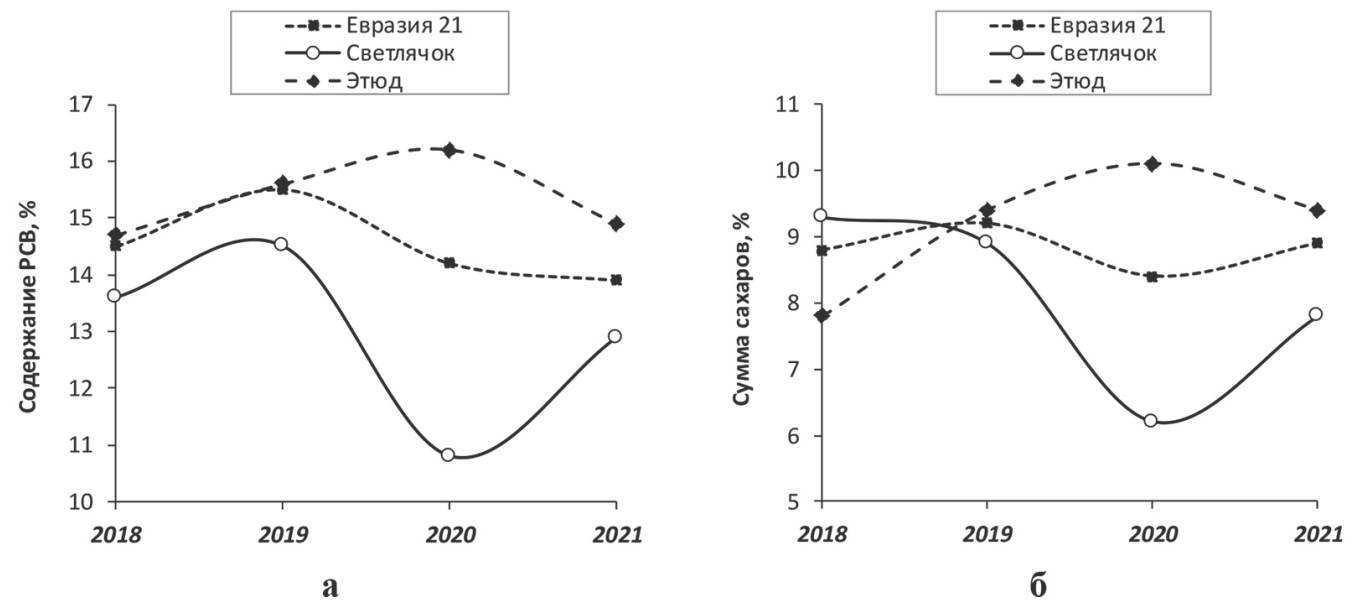

Рис. 2. Динамика содержания растворимых сухих веществ (a) и суммы сахаров (б) в плодах различных сортов сливы за период исследований 
Витамин С играет важную роль в окислительно-восстановительных процессах и благотворно влияет на организм человека. Его содержание варьировало по годам в пределах 4,3-10,5 мг/100 г (рис. 3a). В изученных образцах в среднем за период исследования содержалось от 7,7 $\pm 1,3$ мг/100 г (у сорта 'Этюд’) до 7,2 $\pm 1,08$ мг/100 г ('Светлячок').

Содержание кислот в плодах сливы в зависимости от сорта и условий года находилось в пределах от 1,5 \% у сорта 'Светлячок' до 3,4 \% у сорта 'Евразия 21' (рис. 3б). Стабильно высокие показатели данного признака наблюдались у сортов 'Евразия 21' (2,5-3,4 \%) и 'Этюд' (2,1-2,5\%). Содержание кислот в плодах сорта 'Светлячок' было ниже - 1,5-2,6\%.
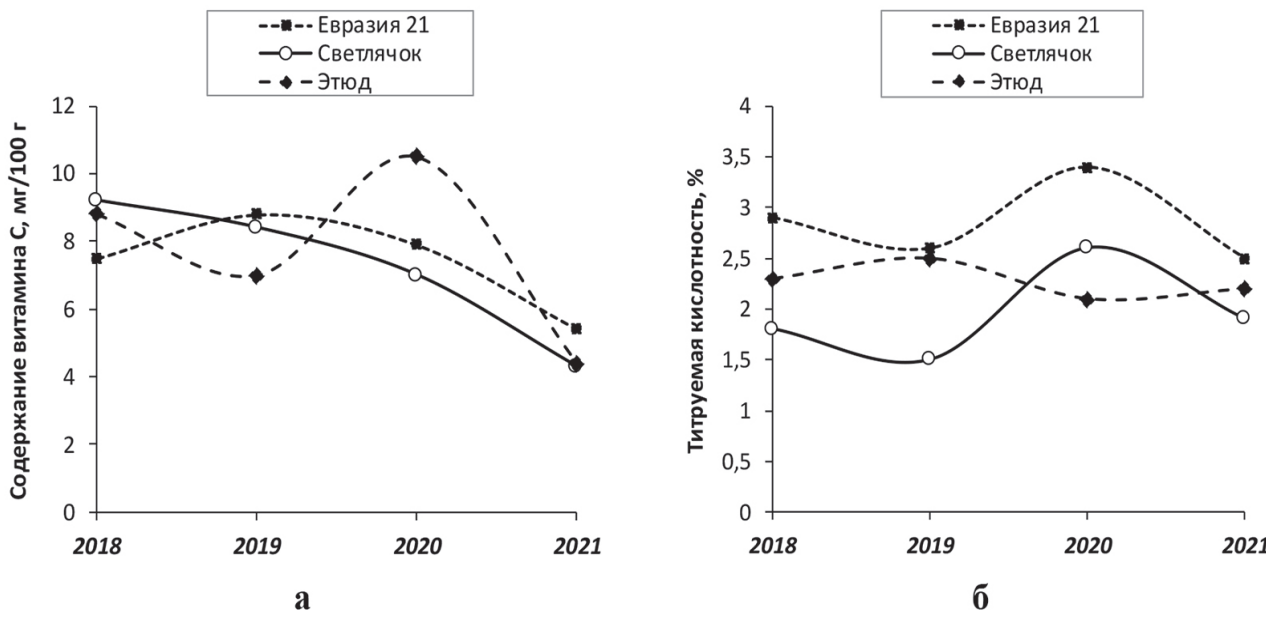

Рис. 3. Динамика содержания

витамина C (a) и титруемой кислотности (б) в плодах различных сортов сливы за период исследований

Вкус плодов сливы во многом определяется соотношением накапливаемых сахаров и кислот. Частное от деления массовой доли сахаров на массовую долю кислот, содержащихся в плодах, выражается безразмерной величиной и называется сахарокислотным индексом. За изученный период наиболее высокие среднегодовые значения сахарокислотного индекса отмечены у сортов 'Светлячок' и 'Этюд', соответственно 4,4 и 4,1 (рис. 4).

У изучаемых сортов сливы за период проведения исследований положительные корреляции высокого уровня отмечены между содержанием растворимых сухих веществ и суммой сахаров в плодах (на уровне 0,99 ), а также между содержанием витамина С и титруемой кислотностью $(0,88)$. 


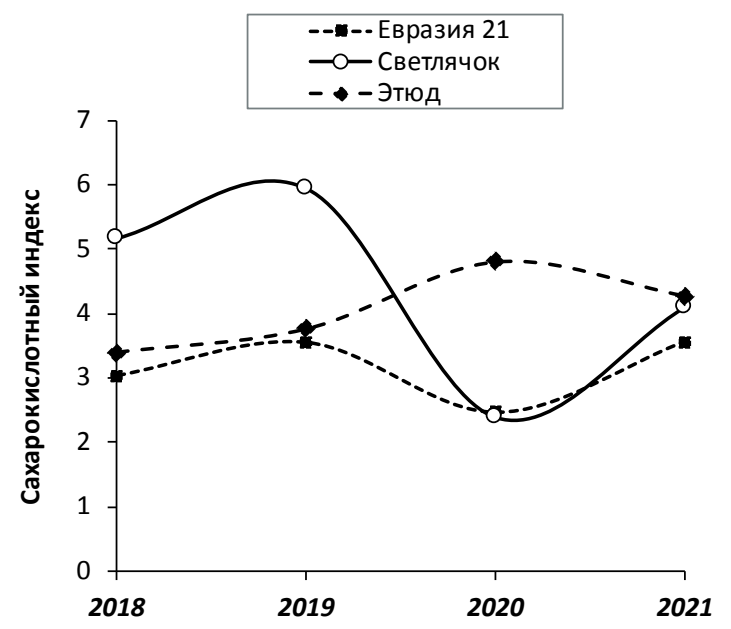

Рис. 4. Динамика сахарокислотного индекса в плодах различных сортов сливы за период исследований

Отмечена отрицательная зависимость между показателями температурного режима летнего периода и содержанием аскорбиновой кислоты (наиболее высокие уровни отмечены у сортов 'Евразия 21' и 'Светлячок' - соответственно -0,91 и -0,68). Нами ранее отмечалась положительная корреляция высокого уровня между накоплением витамина С и количеством выпавших осадков [3], что соотносится с полученными данными (коэффициенты корреляции 0,73 и 0,74 у сортов 'Евразия 21' и 'Светлячок' соответственно).

Между значением суммы осадков летнего периода и накоплением сахаров и РСВ отмечены положительные корреляции разного уровня.

Заключение. Проведённые исследования выявили значительные различия в химическом составе плодов сливы в зависимости от условий вегетации. В среднем за изучаемые годы по наибольшему уровню накопления РСВ и сахаров отмечен сорт 'Этюд’. Меньшее количество титруемых кислот и наиболее высокие показатели сахарокислотного индекса выявлены в плодах сорта 'Светлячок'. Наибольшее количество витамина С в отдельные годы накапливалось в плодах сортов 'Этюд' и 'Евразия 21'. Были выявлены отрицательные корреляции между месячными значениями температуры и содержанием витамина С у сортов 'Евразия 21' и 'Светлячок' на уровне -0,91 и -0,68. Также отмечено положительное влияние достаточного увлажнения на уровень накопления сахаров, РСВ и витамина С в плодах сливы. 


\section{Библиографический список}

1. Богданов Р.Е., Жбанова Е.В. Химико-технологическая оценка сортов сливы // Современные проблемы технологии производства, хранения, переработки и экспертизы качества сельскохозяйственной продукции: материалы Международной научно-практической конференции. - Мичуринск, Мичуринский ГАУ, 2007. - С. 31-35. - ISBN 978-5-94664-111-1. 2. Дубровская О.Ю. Биохимический состав плодов сортов и форм сливы и выделение лучших генотипов для селекционного использования и переработки: дис. ... канд. с.-х. наук. - Мичуринск, 2015. - 130 с.

3. Дубровская О.Ю., Богданов Р.Е. Влияние климатических условий на накопление аскорбиновой кислоты в плодах сливы // Современные тенденции развития науки и технологий. - 2016. - С. 98-100. - ISSN 2413-0869.

4. Влащик Л.Г., Родионова Л.Я. Методы определения титруемой кислотности сельскохозяйственной продукции // Методические указания к лабораторно-практической работе, ФГБОУ ВПО «Кубанский государственный аграрный университет». - Краснодар, 2011. - $10 \mathrm{c}$.

5. ГОСТ 28562-90 Продукты переработки плодов и овощей. Рефрактометрический метод определения растворимых сухих веществ - М.: Стандартинформ, 2010. - 12 с. 6. ГОСТ 8756.13-87 Продукты переработки плодов и овощей. Методы определения сахаров. - М.: Стандартинформ, 2010. - 11 с.

7. ГОСТ 25555.0-82 Продукты переработки плодов и овощей. Методы определения титруемой кислотности. - М.: Стандартинформ, 2010. - 4 с.

8. Методы биохимического исследования растений / под ред. А.И. Ермакова. - Л.: Агропромиздат, 1987. - 430 с.

9. Заремук Р.Ш., Богатырева С.В., Смелик, Т.Л. Качество плодов перспективных сортов сливы домашней для Краснодарского края // Плодоводство и виноградарство юга России. - 2014. - № 28(04). - [Электронный ресурс]. - Режим доступа: http:// journal.kubansad.ru/pdf/14/04/03.pdf (дата обращения 13.09.2021). - ISSN 2219-5335. 10. Осипов Г.Е., Осипова 3.А. Химический состав свежих плодов у сортов и гибридов сливы селекции Татарского НИИСХ // Садоводство и виноградарство. - 2009. - № 1. - С. 16-17. - [Электронный ресурс]. - Режим доступа: elibrary_14567557_13371102.pdf (дата обращения 13.09.2021). - ISSN 0235-2591.

11. Программа и методика сортоизучения плодовых, ягодных и орехоплодных культур / под ред. Е.Н. Седова, Т.П. Огольцовой. - Орёл: ВНИИСПК, 1999. - 608 с. ISBN 5-900705-15-3

12. Шамаева И.З. Биохимические особенности сортов сливы домашней в условиях предгорной зоны Кабардино-Балкарской республики // Центральный научный вестник. - Воронеж, 2018. - Т. 3. - № 8(49). - С. 34-36. [Электронный ресурс]. - Режим доступа: http://cscb.su/n/030801/030801019 (дата обращения 15.09.2021). - ISSN 2499-9989.

13. Dugalic K., Sudar R., Viljevac M., Josipovic M., Cupic T. Sorbitol and Sugar Composition in Plum Fruits Influenced by Climatic Conditions // Journal of Agricultural Science and Technology. - 2014. - Vol. 16. - P. 1145-1155. - [Electronic Resources]. - Access mode: https://www.researchgate.net/publication/264710873_Sorbitol_and_Sugar_Composition_in_Plum_Fruits_Influenced_by_Climatic_Conditions (accessed: 13.09.2021).

\section{ANALYSIS OF LONG-TERM DYNAMICS OF THE CHEMICAL COMPONENTS CONTENT IN PLUM FRUITS}


Глава 6. Физиология и биохимия растений

\author{
Dubrovskaya O.Yu., Zhbanova Ye.V., Bogdanov R.Ye. \\ Federal State Budgetary Scientific Institution \\ "I.V. Michurin Federal Scientific Centre", \\ Michurinsk,Russia,e-mail:popova_olya8888@mail.ru
}

The dynamics of the chemical components content at plum fruits was studied for the growing seasons 2018-2021, significantly different in terms of average monthly temperatures and precipitation amounts. On average, during the study period, $10.8-16.2 \%$ of soluble solids, $8.1-9.2 \%$ of sugars, $1.5-3.4 \%$ of titrated acids, $-4.3-10.5 \mathrm{mg} / 100 \mathrm{~g}$ of vitamin $\mathrm{C}$ accumulated in fruits. The sugar-acid index varied from 4.1 to 4.4 . In the studied plum cultivars during the research period, positive correlations of a high level were noted between the content of soluble solids and the amount of sugars in the fruit (at the level of 0.99), as well as between the content of vitamin $\mathrm{C}$ and titrated acidity (0.88). The positive effect of sufficient moisture on the level of accumulation of sugars, soluble solids and vitamin $\mathrm{C}$ in fruits was also recorded. A negative correlation was observed between the values of the average monthly summer temperatures and the vitamin $C$ content.

Key words: plum, chemical compositions of fruits, soluble solids, total sugars, vitamin $\mathrm{C}$ content, titratable acidity, climatic conditions.

doi: 10.31360/2225-3068-2021-79-107-117

\title{
ЭКСПЕРИМЕНТАЛЬНЫЙ АНАЛИЗ ЗАСУХОУСТОЙЧИВОСТИ ЛИСТЬЕВ КОЛЛЕКЦИИ КЛОНОВЫХ ПОДВОЕВ ЯБЛОНИ СЕЛЕКЦИИ МИЧУРИНСКОГО ГОСУДАРСТВЕННОГО АГРАРНОГО УНИВЕРСИТЕТА
}

\author{
Дубровский М.Л., Кружков Ан.В., Чурикова Н.Л. \\ Федеральное государственное бюджетное \\ образовательное учреждение высшего образования \\ «Мичуринский государственный аграрный университет», \\ 2. Мичуринск, Россия, е-mail: element68@mail.ru
}

Выявлены различия засухоустойчивости листьев у 46 клоновых подвоев яблони, полученных в Мичуринском государственном аграрном университете. Потери воды листьями изучаемых генотипов за первые 2 час отмечены в диапазоне $12,7-64,2 \%$, через 4 час - 20,3-86,5\%, а спустя 24 час с начала эксперимента - 55,3-94,6 \%. За сутки потеря воды завядающими листьями составила $79,9 \pm 1,7$ \% в среднем по генотипам. Наиболее высокая водоудерживающая способность листьев отмечена у подвойных форм яблони 2-3-8, 2-3-19, 2-9-56, 5-27-1, 9-1-1, 9-1-2, которые за 24 час потеряли 55,3-62,7 \% воды. Среди генотипов с антоциановой пигментацией тканей отмечены более высокие значения показателей удельной фотосинтетической активности 